\title{
Risk factors for heat related death during the August 2003 heat wave in Paris, France, in patients evaluated at the emergency department of the Hôpital Européen Georges Pompidou
}

\author{
A Davido, A Patzak, T Dart, M P Sadier, P Méraud, R Masmoudi, N Sembach, T H Cao
}

Emerg Med J 2006;23:515-518. doi: 10.1136/emj.2005.028290

\begin{abstract}
Objectives: This study sought to determine the risk factors for short term mortality in the victims of the heat wave of August 2003 in France from among patients evaluated in our emergency department (ED). It was hypothesised that age, temperature, and some long term therapies and pre-existing pathologies were factors associated with short term mortality.

Methods: A retrospective analysis of a seven day period. Four experts decided blindly, in pairs, whether a patient had presented with a heat related problem. Inclusion criteria were: core temperature $\geqslant 38^{\circ} \mathrm{C}$ and/ or clinical signs of dehydration. Comparisons were made between the survivors and one month nonsurvivors for 57 different items. Short term mortality was defined as death in the ED or within the first month of the ED visit. Results: Of 841 patients attending the ED in the study period, 165 were included in the study, of which most were elderly women. Thirty one (18.8\%) died within one month. Factors associated with short term mortality were: a greater degree of dependent living; more severe clinical condition on admission (higher temperature and heart rate, lower blood pressure, hypoxia, and altered mental status); higher values of blood glucose, troponin, and white blood cell count; lower values of serum protein and prothrombin levels; pre-existing ischaemic cardiomyopathy; pneumonia as associated infection; and previous psychotropic treatment. The total number of survivors at one year was 91.

Conclusions: Although this study is limited because of the small sample size, the results have helped determine factors useful for future identification of patients at greatest risk of death in order to implement a more efficient patient care protocol.
\end{abstract}

See end of article for authors' affiliations

Correspondence to: Dr A Davido, Département d'Accueil des Urgences, Hôpital Européen Georges Pompidou, 20 rue Leblanc, 75015 Paris- France; alain.davido@egp. ap-hop-paris.fr

Accepted for publication 24 January 2006

h August 2003, France experienced an unusual and severe heat wave, responsible for an estimated 14802 excess deaths during a period of 20 days. In Île-de-France, between 4 August and 12 August 2003, maximum temperatures were higher than $35{ }^{\circ} \mathrm{C}$, and the minimum were never lower than $20{ }^{\circ} \mathrm{C}$. In this region (which includes Paris) mortality increased to over $130 \% ; 33 \%$ of all deaths registered in France during this period. ${ }^{1}$ Normally Île-de-France has a temperate climate, and it is rare to have air conditioning in homes and hospitals. The heat wave caused an influx of patients to French emergency services.

Our emergency department (ED) is an adult urban teaching emergency service which is part of the university hospital system of the Public Assistance Hospitals of Paris (AP-HP). Our yearly attendance is 43000 patients. Between 8 August and 14 August 2003, the number of patients attending our ED increased by about 10\% compared with the previous year.

Until now, studies performed in the setting of heat wave have essentially concerned heat stroke. ${ }^{23}$ This condition requires a fever of $\geqslant 40{ }^{\circ} \mathrm{C}$ and altered mental status, and is the best defined of all heat related illnesses. Studies concerning all other clinical presentations, whether heat stress or heat exhaustion, in which signs and symptoms are related to water or salt depletion while the core temperature may remain normal, are rare. There have been some epidemiological studies concerning patients in whom the cause of death may be heat related, for instance, Semenza et al. ${ }^{4}$ However, there is a lack of clinical studies focusing directly on victims of heat waves triaged in emergency services. Their risk of death is unknown.

Our study aimed to determine the factors associated with short term mortality in patients who were seen at our hospital with a heat related medical problem during the seven day period from 8 August to 14 August 2003. We hypothesised that age, temperature, some long term therapies such as psychotropic or diuretic medications, and some preexisting pathologies were factors associated with short term mortality

\section{METHODS}

\section{Review of charts and selection of patients}

The charts of all patients evaluated in the ED between 8 August and 14 August 2003 were reviewed retrospectively by a pair of emergency medicine experts (pair 1: AP and MPS: pair 2: RM and NS). All the four experts completed a standardised abstraction form. In each pair, each expert decided independently and blindly from the other expert whether a patient was to be included in the study based on the criteria for inclusion (see below), and followed the data collection method. In case of non-agreement between the two experts who formed a pair (AP-MPS and RM-NS), a third expert (always $\mathrm{AD}$ ) reviewed the case and made the decision after considering the arguments of the pair of experts.

Before starting the chart review, the expert reviewers underwent training over several sessions. The four experts were trained to perform a blinded, complete evaluation of 
medical records including the ED chart and, whenever available, the Emergency Medical Services sheet, the general practitioner referral letter, and the subsequent hospital reports. During the training period, the quality of the abstraction of the essential data and the concordance between the judgments of the two experts of a pair and between the pairs were evaluated by cross-comparison of the charts. The results showed a high degree of agreement in a short period of time.

The inclusion criteria were core temperature $\geqslant 38{ }^{\circ} \mathrm{C}$ and/or clinical signs of dehydration. The only criterion for noninclusion was premature departure of a patient from the emergency room before a sufficient medical evaluation could be done.

\section{Measures included and data processing}

A computerised record of 57 items including demographic information, clinical findings, and laboratory data, was entered for each patient included in the study. The laboratory results and clinical data included were the first values recorded for each patient in their chart. In our ED, an auricular thermometer is used to measure the core temperature. However, if the core temperature had been measured with an ausicular thermometer by the French Medical Emergency Service (SAMU) staff before the patient arrived at the emergency room, the highest value was recorded. The patient was considered to be dehydrated if the expert found a mention in the medical records of either the term "clinically dehydrated" or at least two of the following clinical signs: decreased skin turgor with prominent cutaneous skin folds; dry mucous membranes; dry axillae; or sunken ocular globes. Physical dependence/autonomy was evaluated by scoring for each activity of the activities of daily living (ADL) scale using information gathered from the patient's chart. ${ }^{5}$ Three stages of ADL physical disability were defined: independence (global score $=0$ ), partial dependence (global score $=1-$ 3 ), and total dependence (global score $=4-6$ ). The experts had to check if an infection was mentioned in the medical records during the initial ED evaluation, but they did not have to consider if it was a cause or a consequence. The experts had to check for every documented infection with a positive culture (urine or blood) within the first 24 hours or chest $x$ ray taken during the first 48 hours consistent with pneumonia, and its presence was defined as an associated infection.

Any chronic pre-existing medical condition was assessed and recorded using the International Classification of Diseases, 10th edition. ${ }^{6}$ Following consensus between our staff, the diagnoses were grouped into 11 categories.

Short term mortality was defined as death in the ED or within the first month following the ED visit. To follow up the outcome of our cohort, but without considering the cause of death, we contacted either the patients or their families at 6 months and 12 months following their initial visit to the ED.

\section{Statistical methods}

We analysed the data using Stata (StataCorp LP) software for the calculations. Comparison of two proportions was done using the $\chi^{2}$ test or the Fisher's exact test, as appropriate. Comparison of two means was done with Student's $t$ test. A p value $<0.05$ was considered significant. The results are presented as mean (SD) or percentage (number). The percentages were calculated relative to the total number of patients for whom data were available, because in this retrospective review, not all data were available for all patients.
Table 1 Comparison of clinical and demographic data of survivors and non-survivors

\begin{tabular}{|c|c|c|c|}
\hline & $\begin{array}{l}\text { Survivors } \\
(n=134)\end{array}$ & $\begin{array}{l}\text { Non-survivors } \\
(\mathrm{n}=31)\end{array}$ & $\mathbf{p}$ \\
\hline \multicolumn{4}{|l|}{ Demographic data } \\
\hline Women* & $65.6(88)$ & $80.7(25)$ & NS \\
\hline Age (years)† & $83.3(13.4)$ & $86.2(9.0)$ & NS \\
\hline \multicolumn{4}{|l|}{ Brought in from:* } \\
\hline Home & $80.5(103)$ & $73.3(22)$ & NS \\
\hline Nursing home & $11.7(15)$ & $23.3(7)$ & \\
\hline Street & $7.8(10)$ & $3.3(1)$ & \\
\hline Dependence (total or partial)* & $43.5(57)$ & $78.3(18)$ & $<0.005$ \\
\hline Cachectic state $^{*}$ & 6.7 (9) & $17.2(5)$ & NS \\
\hline \multicolumn{4}{|l|}{ Clinical data } \\
\hline Temperature $\left({ }^{\circ} \mathrm{C}\right) \dagger$ & $39.0(1.1)$ & $40.1(1.5)$ & $<0.0001$ \\
\hline Systolic BP (mm Hg)† & $141(28)$ & $118(39)$ & $<0.0001$ \\
\hline Diastolic BP (mm Hg)† & 71 (15) & $57(23)$ & $<0.0001$ \\
\hline Unobtainable BP* & $0.0(0)$ & $9.7(3)$ & $<0.005$ \\
\hline Cardiac rate (beats/min)† & 93.7 (32.7) & $117.5(22.5)$ & $<0.0001$ \\
\hline $\mathrm{SpO}_{2}$ on room air (\%)† & $93.9(3.0)$ & $86.1(9.2)$ & $<0.0001$ \\
\hline Altered mental status* & $36.6(49)$ & $96.8(30)$ & $<0.0001$ \\
\hline Seizures* & $3(4)$ & $20(6)$ & $<0.005$ \\
\hline Heat stroke* & $11.9(16)$ & $77.4(24)$ & $<0.0001$ \\
\hline
\end{tabular}

\section{RESULTS}

Of the 841 patients seen in our ED during the seven day period (8-14 August 2003), 165 (19.6\%) fulfilled the criteria for inclusion. These were elderly patients (mean (SD) age: 83.8 (12) years), predominantly women (69.1\%) and dependent $(48.7 \%)$. A total of 139 patients were hospitalised, of whom 8 were directly transferred to the intensive care unit (ICU). Only 26 patients were discharged from the ED.

Within the first month, there were 31 deaths among the hospitalised patients (mortality 18.8\%). None of the discharged patients died during that period. The patients who died differed from the patients who survived essentially by their greater degree of assisted or dependent living and by a more abnormal initial clinical presentation. Elevated pulse and temperature, lower blood pressure, hypoxia, and altered mental status were more frequent among non-survivors (table 1).

In terms of laboratory data, blood glucose and troponin levels and the white blood cell count were higher among patients who died, and blood protein and prothrombin levels were lower. We did not find any significant differences between the two groups with regard to sodium and potassium levels, urea, creatinine, C-reactive protein (CRP) or creatine phosphokinase (CPK) (table 2).

Distribution of the most frequently occurring comorbidities is shown in table 3. At least 112 patients had a chronic

Table 2 Comparison of laboratory data of one month survivors and non-survivors*

\begin{tabular}{lccl}
\hline & $\begin{array}{l}\text { Survivors } \\
(\mathbf{n}=134)\end{array}$ & $\begin{array}{l}\text { Non-survivors } \\
(\mathbf{n}=31)\end{array}$ & $\mathbf{p}$ \\
\hline Blood glucose (mmol/l) & $7.8(3.3)$ & $12.4(6.3)$ & $<0.0001$ \\
Sodium (mmol/l) & $137.6(8.8)$ & $138.6(10.8)$ & NS \\
Potassium (mmol/l) & $3.9(0.7)$ & $3.8(0.8)$ & $\mathrm{NS}$ \\
Blood urea nitrogen (mmol/l) & $12.2(8.3)$ & $13.2(9.5)$ & $\mathrm{NS}$ \\
Creatinine ( $\mu \mathrm{mol} / \mathrm{l})$ & $142.0(117.4)$ & $157.0(58.0)$ & $\mathrm{NS}$ \\
Serum protein (g/l) & $69.1(9.1)$ & $63.7(9.7)$ & $<0.005$ \\
CRP (mg/l) & $22.6(42.0)$ & $40.9(81.2)$ & $\mathrm{NS}$ \\
Troponin lc ( $\mu \mathrm{g} / \mathrm{l})$ & $0.2(0.6)$ & $7.2(22.0)$ & $<0.05$ \\
WBC $\left(/ \mathrm{mm}^{3}\right)$ & $11461(6500)$ & $16817(6181)$ & $<0.0001$ \\
Prothrombin (\%) & $72.0(17.3)$ & $61.0(16.0)$ & $<0.005$ \\
CPK (UI/l) & $1280.5(4379.6)$ & $914.1(708.3)$ & $\mathrm{NS}$ \\
\hline *Values are mean (SD). & & & \\
\hline
\end{tabular}


Table 3 Comparison of the prevalence of pre-existing pathologies and associated infections in survivors and non-survivors

\begin{tabular}{|c|c|c|c|}
\hline Pre-existing pathology & $\begin{array}{l}\text { Survivors } \\
(n=134)\end{array}$ & $\begin{array}{l}\text { Non-survivors } \\
(n=31)\end{array}$ & $\mathbf{p}$ \\
\hline Dementia & $9.0(12)$ & $9.7(3)$ & NS \\
\hline Parkinson's disease & $7.5(10)$ & $9.7(3)$ & NS \\
\hline Depression & $9.0(12)$ & $6.5(2)$ & NS \\
\hline Ischaemic cardiomyopathy & $13.4(18)$ & $32.3(10)$ & $<0.05$ \\
\hline Congestive heart failure & $6.0(8)$ & $9.7(3)$ & NS \\
\hline Arrhythmias & $14.9(20)$ & $9.7(3)$ & NS \\
\hline Hypertension & $19.4(26)$ & 9.7 (3) & NS \\
\hline Diabetes & $9.0(12)$ & $6.5(2)$ & NS \\
\hline Stroke (past history) & $5.2(7)$ & $0.0(0)$ & NS \\
\hline $\begin{array}{l}\text { Chronic obstructive } \\
\text { pulmonary disease }\end{array}$ & $6.0(8)$ & $3.2(1)$ & NS \\
\hline Cancer & $3.0(4)$ & $6.5(2)$ & NS \\
\hline \multicolumn{4}{|l|}{ Associated infections } \\
\hline \multicolumn{4}{|l|}{ Urine culture: } \\
\hline Done & $27.0(34)$ & $58.1(18)$ & 0.001 \\
\hline Positive & $52.9(18 / 34)$ & $50.0(9 / 18)$ & NS \\
\hline \multicolumn{4}{|l|}{ Blood culture: } \\
\hline Done & $28.8(36)$ & $53.3(16)$ & $<0.05$ \\
\hline Positive & $11.1(4 / 36)$ & $18.8(3 / 16)$ & NS \\
\hline \multicolumn{4}{|l|}{ Chest $x$ ray: } \\
\hline $\begin{array}{l}\text { Done } \\
\text { Infiltrate }\end{array}$ & $\begin{array}{l}72.6(90) \\
67(6 / 90)\end{array}$ & $\begin{array}{l}83.9(26) \\
23](6 / 26)\end{array}$ & NS \\
\hline
\end{tabular}

pre-existing medical condition. Infections were screened for depending on the initial clinical presentation, and screening was done more often in the patients who died than in those who survived. Also the screening was positive more often in the patients who died, but the difference was significant only for pulmonary pathology (table 3 ).

Of the 165 patients included in the study, $128(77 \%)$ had long term medical therapy. The survivors were less often on psychotropic medications than non-survivors (59 (46.1\%) $v$ $15(68.2 \%) ; \mathrm{p}<0.05)$. However, the difference in the percentage of patients on diuretics $(29(22.8 \%) \vee 6(27.3 \%)$; NS) and cardiotropes $(68(50.8 \%) \vee 12(38.7 \%)$; NS) in the two groups was not significant.

We were able to conduct long term follow up of 132 of the 134 patients who survived beyond the first month. Thus only two patients were lost to follow up. At six months, 26 of the 132 survivors had died. At 12 months, the number of survivors was 91.

\section{DISCUSSION}

Our study cohort consisted of elderly patients, predominantly women, with a high rate of dependency in their activities of living. Older people are usually the victims of heat waves, especially once they are less independent. ${ }^{4}{ }^{7}$ They are unable to appreciate the higher temperatures and protect themselves effectively from the effects in the usual ways. During the study period, the average age of the patients seen in our ED was much younger ( 54 years).

When we looked at the short term risks of mortality in our elderly study population, it correlated with only the degree of dependence and not with patient age. A number of independent clinical factors had a bad prognosis: higher body temperature, lower blood pressure, a notable tachycardia, and altered mental status. Each individual clinical sign reflects an error in heat adaptation and/or a failure of the mechanisms that usually compensate for the effects of heat on a living organism.

We did not find the electrolyte abnormalities to be of any short term prognostic value. This may be explained by the distribution of serum sodium levels in our patients, which varied widely between hyponatraemia and hypernatraemia, with a near normal average. The renal function on admission, as reflected in the urea and creatinine values, was also not a risk factor for mortality, probably because it also reflects preexisting clinical conditions. Serum protein levels, which were lower in non-survivors, probably indicate a poorer baseline nutritional status. Patients who died had higher glucose levels, higher white blood cell counts and a lower prothrombin level, probably due to a systemic inflammatory response, which has been previously described in heat stroke. ${ }^{3}$ The troponin level, a risk factor for mortality, reflected more frequent myocardial involvement. The pathophysiological mechanisms triggered by a heat wave are known to favour myocardial ischaemia and thrombogenesis as part of the coagulation cascade. ${ }^{8}$ We also found that, in our population, the patients who had chronic pre-existing ischaemic cardiomyopathy were particularly susceptible.

We did not find any significant differences between survivors and non-survivors with regard to other pre-existing pathologies. The small sample size does not allow us to draw any further conclusions. Neuropsychiatric pathology (dementia, Parkinson's disease, depression, stroke) which usually makes patients more dependent was not individually identified, although the patient's degree of autonomy was a significant prognostic factor in the study population as a whole. Among long term medical therapies, psychotropic medications were the only ones to increase the risk of death in our study population, which is understandable given their deleterious effects on thermoregulation. ${ }^{9}$ Neuroleptic malignant syndrome or serotonin syndrome was unlikely in our population of patients who had been on psychotropic treatment for a long time. Among other long term therapies, cardiotropes, which alter the cardiovascular response to heat, and diuretics, which can aggravate dehydration, were not found to be risk factors for mortality.

The frequency of associated infections among victims of heat waves has been reported previously in the literature. ${ }^{2}$ Many mechanisms could be implicated, including immunosuppression and bacterial migration due to intestinal ischaemia, both of which have been described in heat stroke. ${ }^{10}$ In our study, only pneumonia was found significantly more frequently in non-survivors; it was often associated with aspiration in the setting of altered mental status.

Despite their poor clinical status, only eight patients were admitted to ICU. This phenomenon can be explained by the following: most of our patients were elderly with a great degree of assisted or dependent living; to be considered for ICU admission, we would have to have known the risk factors for morbidity and mortality associated with heat illness, and we did not have them at the time.

\section{Limitations of the study}

Our present study has some limitations. It was a retrospective analysis with problems usually linked to such research-for example, missing data. However, in the context of natural disasters, all scientific studies are inevitably retrospective. Owing to the small sample size and the probable non-random distribution of missing data we did not perform a multivariate analysis to assess the independent role of each risk factor to avoid spurious conclusions.

\section{Practical implications}

Mortality during heat waves remains high. Our study, although having a small sample size, allowed us to identify several factors associated with short term mortality. These risk factors, the experience acquired during the heat wave, and previously published data allowed us to develop a patient care protocol, to be applied in case of future heat waves likely to occur in France. 
In particular, the victims at greatest risk of death may be rapidly considered for admission to ICU after their initial ED evaluation. Since it is not easy to consider an elderly patient for ICU, all information that can aid in discussions with the intensivists is important. The results of our study offer some criteria for ranking of candidates for ICU admission in case of another heat wave. In the French healthcare system, in the event of a natural catastrophe, extra ICU beds can be made available for patients requiring intensive care. Other studies with larger numbers of patients are needed to determine complementary risk factors and identify subgroups.

\section{ACKNOWLEDGEMENTS}

We would like to thank Dr B Hanke for her help in translating this article. The authors also thank Dr G Chatellier, Département d'Informatique Hospitalière, for his advice.

\section{Authors' affiliations}

A Davido, A Patzak, M P Sadier, P Méraud, R Masmoudi, N Sembach, T H Cao, Département d'Accueil des Urgences, Hôpital Européen Georges Pompidou, (AP-HP); Faculté de Médecine René Descartes Paris 5, Paris, France

T Dart, Département d'Informatique Hospitalière, Hôpital Européen Georges Pompidou (AP-HP); Faculté de Médecine René Descartes Paris 5, Paris, France
Competing interests: none declared

Ethical approval: In France a retrospective chart review is not required to be submitted to an institutional review, which grants us a legal exemption.

\section{REFERENCES}

1 Hémon D, Jougla E. Surmortalité liée à la canicule d'août 2003, Rapport d'étape (1/3).INSERM, 25 septembre, 2003.

2 Dermatte JE, O 'Mara K, Buescher J, et al. Near-fatal heat stroke during the 1995 heat wave in Chicago. Ann Intern Med 1998;129:173-81.

3 Bouchama A, Knochel JP. Heat stroke. N Engl J Med 2003;346:1978-88.

4 Semenza JC, Rubin $\mathrm{CH}$, Falter $\mathrm{KH}$, et al. Heat-related deaths during the July 1995 heat wave in Chicago. N Engl J Med 1996;335:84-90.

5 Katz S. Assessing self-maintenance: activities of daily living, mobility and instrumental activities of daily living. J Am Geriatr Soc 1962;1 10:83-91.

6 World Health Organization. International Classification of Diseases, 10th edition. Geneva: WHO, 1993.

7 Basu R, Samet JM. Relation between elevated ambient temperature and mortality: a review of the epidemiologic evidence. Epidemiol Rev 2002;24:190-202.

8 Keatinge WR, Coleshaw SRK, Easton JC, et al. Increased platelet and red cell count, blood viscosity and plasma cholesterol levels during heat stress, and mortality from coronary and cerebral thrombosis. Am J Med 1986;81:795-800.

9 Bark N. Deaths of psychiatric patients during heat waves. Psychiatr Serv 1998;49:1088-90.

10 Hall DM, Buettner GR, Oberley LW, et al. Mechanisms of circulatory and intestinal barrier dysfunction during whole body hyperthermia. Am J Physiol Heart Circ Physiol 2001;280:H509-H521.

\section{bmjupdates+}

bmiupdates+ is a unique and free alerting service, designed to keep you up to date with the medical literature that is truly important to your practice.

bmjupdates+ will alert you to important new research and will provide you with the best new evidence concerning important advances in health care, tailored to your medical interests and time demands.

Where does the information come from?

bmjupdates+ applies an expert critical appraisal filter to over 100 top medical journals A panel of over 2000 physicians find the few 'must read' studies for each area of clinical interest

Sign up to receive your tailored email alerts, searching access and more...

www.bmjupdates.com 